index ecomunicación | no 12(1) 2022 | Páginas 205-234

E-ISSN: 2174-1859 | ISSN: 2444-3239 | Depósito Legal: M-19965-2015

Recibido el 6_09_2021 | Aceptado el 12_10_2021 | Publicado el 15_01_2022

\title{
VISIONADO COLECTIVO DE CINE EN LA RED SOCIAL TWITCH POR PARTE DE CENTENNIALS: ESTUDIO DE CASO
}

\section{FILM CO-WATCHING ON THE SOCIAL MEDIA TWITCH BY CENTENNIALS: A CASE STUDY}

https://doi.org/10.33732/ixc/12/01Vision

Sergio Gutiérrez Manjón

Universidad Complutense de Madrid sergiogu@ucm.es https://orcid.org/0000-0001-7412-1532

Sergio Álvarez García Universidad Complutense de Madrid sergioalvarezgarcia@ucm.es https://orcid.org/0000-0001-9477-2148

Sergio Mena Muñoz Universidad Complutense de Madrid smenamun@ucm.es https://orcid.org/0000-0001-6121-4991

Financiación a la ayuda a la investigación por contrato CT42/18CT43/18 dentro del Programa de Financiación de la Universidad Complutense de Madrid y el Banco Santander. 
Resumen: La red social Twitch acoge una forma novedosa de visionar colectivamente productos audiovisuales, cuyo público son centennials. Se analiza el caso de las Watch Parties ('fiestas de visionado') que permiten a los usuarios ver películas en tiempo real con un streamer. Tomando como caso de estudio tres Watch Parties del streamer Lynx_Reviewer se realiza una triangulación metodológica: etnografía virtual, análisis de contenido y entrevista semiestructurada. Mediante la exploración del fenómeno se construye un modelo de análisis de consumo colectivo de contenidos gracias a una sistematización descriptiva de los hábitos y usos de consumo de la audiencia estudiando las conversaciones y los mensajes generados en las transmisiones. Los resultados obtenidos muestran que, a pesar de la disparidad de contenidos y canales que emiten en Twitch, este formato sigue un patrón común de emisión, participación, interfaz y tipo de mensajes. Se trata de una experiencia de ocio basada en la construcción colectiva de un contenido desarrollado sincrónicamente con la interacción de la audiencia, que usa referencias y códigos expresivos propios para comunicarse, utilizando las películas como medio para relacionarse dentro de la comunidad.

Palabras clave: redes sociales; Twitch; video grupal; cine; centennials; transmisión en directo.

Abstract: The network Twitch hosts a novel form of collective viewing of audiovisual products, whose audience is centennials. We analyse the case of Watch Parties, which allow users to watch films in real time with a streamer. Taking three Watch Parties of the streamer Lynx_Reviewer as a case study, a methodological triangulation is carried out: virtual ethnography, content analysis and semi-structured interview. By exploring the phenomenon, a model of analysis of collective consumption of content is constructed thanks to a descriptive systematisation of the audience's consumption habits and uses by analysing the conversations and messages generated in the transmissions. The results obtained show that, despite the disparity of content and channels broadcasting on Twitch, this format follows a common pattern of broadcasting, participation, interface and type of messages. It is a leisure experience based on the collective construction of content developed synchronously with the interaction of the audience, which uses its own references and expressive codes to communicate, using films as a means of interaction within the community.

Keywords: Social Media; Twitch; Watch Party; Cinema;

Centennials; Streaming. 


\section{Introducción}

Las redes sociales son un entorno que forma parte del consumo audiovisual diario de la ciudadanía, especialmente entre los denominados centennials o Generación Z, personas nacidas entre mediados de los 90 y mediados de la década del 2000 (Turner, 2015; Prakashyadav y Jyotsna, 2017). Dicho grupo presenta unas características de consumo específicas asociadas al uso continuo de las redes sociales: «Centennials spent a lot of time online. Generation $\mathrm{Z}$ is the first to get into in all things related to mobile and digital, spending an average of 11 hours a week, not including work and e-email1» (Sharma, 2019: 41). La manera en que participan a la hora de emplear su tiempo de ocio diverge de los millennials tanto en su forma de interactuar socialmente como en su manera de intervenir en la co-creación del espacio virtual (Llopis-Amorós, 2019), ya que los centennials desarrollan sus relaciones en las redes sociales y muestran su compromiso social en dicho entorno.

Entre los años 2020 y 2021, de acuerdo con el Estudio Anual de Redes Sociales, se incrementó el consumo de redes sociales. Este aumento fue debido en parte a la emergencia sanitaria provocada por la pandemia de la COVID-19, lo que provocó restricciones a la movilidad y supuso una reducción drástica en la actividad social de las personas. En consecuencia, parte de la población cambió su forma de relacionarse adaptándola al entorno digital (IAB, 2021).

Este mismo informe muestra que entre las redes sociales que más crecieron en 2021, principalmente entre los centennials, destaca la plataforma de Twitch.tv que permite realizar transmisiones en directo. Twitch tuvo un consumo medio diario de 1 hora y 40 minutos, siendo la plataforma audiovisual preferida entre la población de 16 a 24 años, con un 35\% de dicha población utilizándola frecuentemente (IAB, 2021).

A raíz de la situación ocasionada por la COVID-19, las plataformas de contenido bajo demanda (VOD) desarrollaron aplicaciones para que sus clientes pudieran visionar telemáticamente con sus allegados películas y series dentro de su catálogo. Se trata de una función que permite a los usuarios ver un contenido de la plataforma de manera simultánea con otros usuarios y comentarlo mediante un chat en tiempo real (Avendaño, 2020). De este modo, surgen iniciativas como Watch Party en Prime Video o Teleparty en Netflix.

\footnotetext{
1 Traducción propia: Los centennials pasan mucho tiempo en Internet. La Generación Z es la primera en adentrarse en todo lo relacionado con el móvil y lo digital, pasando una media de 11 horas a la semana, sin incluir el trabajo.
} 


\subsection{Hábitos de consumo de centennials en redes sociales}

La convergencia digital ${ }^{2}$ ha influido sobre los hábitos que tienen los usuarios a la hora de utilizar los medios para informarse o entretenerse. Con la consolidación de Internet, las personas han cambiado el modo en que consumen contenidos audiovisuales, pues ahora se les ofrecen nuevos productos y nuevas formas de relacionarse con ellos (Francisco-Lens y Rodríguez-Vázquez, 2020; Navarro y Vázquez, 2020).

Las redes sociales se desarrollan con la vocación de reunir a personas, sean conocidas o no, para que interactúen entre sí (Rubio-Romero, Jiménez y Barón-Dulce, 2019). En este sentido, los medios sociales marcan nuevas formas de consumo entre los jóvenes especialmente para establecer relaciones interpersonales (Vizcaíno-Laorga, Catalina-García y de Ayala-López, 2021). Así, los medios sociales han promovido el fenómeno de la cultura de la participación (Jenkins, Ito y Boyd, 2015), en el que se incita al potencial consumidor a colaborar en la creación del entorno virtual mediante aportaciones propias, las cuales son gratificadas por la red social con recompensas que premian la motivación extrínseca (Lazo, 2017) a través del número de 'me gusta', de seguidores o de las veces que se comparte una publicación.

La participación de los usuarios es entendida no solo como una interpretación activa del contenido que consumen, sino que también implica la producción de contenido propio e interacción con el medio (Castro-Mariño, 2018). En consecuencia, esta participación social posibilita, por un lado, nuevos canales de comunicación que permitan que los usuarios interactúen entre sí (Masip, Ruiz-Caballero y Suau, 2019) y, por otro lado, que dicha participación pueda influir en la emisión del contenido (Rangel y Velasco, 2017).

No obstante, esta cultura de la participación no es entendida sin la aparición de nuevos soportes para la difusión audiovisual que han permitido visionar contenidos en segundas pantallas, como los móviles. Gracias a ellos se han facilitado nuevas experiencias digitales al posibilitar una mayor interactividad en el consumo multipantalla (Echegaray y Peñafiel, 2013). A este respecto, los usuarios que consumen contenidos en la primera pantalla, como la televisión, comparten sus opiniones a través de la segunda pantalla, el móvil, en redes sociales (Halpern, Quintas-Froufe y Fernández-Medina, 2016). Según Ramos y Ortega-Mohedano (2017), cuanto más joven es el usuario, mayor consumo multipantalla realiza y, además, utiliza casi permanentemente la segunda pantalla para comentar con su red de amistades lo que consume en la primera pantalla. De este modo, se suele complementar el consumo audiovisual con la recepción

\footnotetext{
2 Proceso que posibilita consumir contenidos desde distintos dispositivos gracias al desarrollo de la conectividad y la digitalización de dichos contenidos (Salaverría, García y Masip, 2008).
} 
de recursos procedentes de Internet a la vez que se interactúa a través de chat y redes sociales (Lacalle y Gómez, 2017). Así pues, estos usuarios considerados como prosumidores han encontrado en las redes sociales «un espacio de comunicación horizontal para distribuir sus contenidos y en el celular una herramienta de creación multidiscursiva» (Karbaum, 2018: 231).

Teniendo en cuenta el desarrollo de las redes sociales, se observa que se trata de entornos muy poblados en un ecosistema fundamentalmente digital, en el que la Generación $\mathrm{Z}$ ha crecido en un contexto mediático marcado por la evolución de Internet (Martínez-Sala, Barrientos-Báez y Caldevilla, 2021). Sin embargo, a pesar de su estrecha vinculación con estas redes, centennials y millennials tienen formas diferentes de interactuar con este tipo de medios.

Los centennials están más vinculados con las redes sociales y, en consecuencia, su comportamiento social se produce en estos medios (Prakashyadav y Jyotsna, 2017). La Generación $\mathrm{Z}$ también diverge con respecto a los millennials, generación nacida entre principios de los 80 y mediados de los 90 (DeVaney, 2015), en que prefieren entornos virtuales en los que los contenidos desaparecen rápidamente y participan del acto inmediato (Cerezo, 2016). Del mismo modo, los centennials consumen más contenidos frente al teléfono que los millennials, pues lo consideran su principal fuente de entretenimiento y un elemento esencial para desarrollar su vida social (Ramos y Ortega-Mohedano, 2017).

\subsection{Twitch como medio social y audiovisual}

A lo largo de los últimos años ha aumentado la popularidad de la emisión de contenidos en directo. En el primer trimestre de 2021 Twitch alcanzó su máximo histórico con 6300 millones de horas vistas frente a los 1060 millones de horas de Facebook Gaming y los 1370 millones de YouTube Gaming (Europapress, 2021). Se trata de un tipo de contenido propio de Internet en el que se crea mediante la interacción con el público un producto de entretenimiento. En 2025 se estima que alcanzará una audiencia media de 800 millones de espectadores en todo el mundo (Godoy, 2021). Debido a su auge, en los últimos años han surgido diferentes servicios de streaming ${ }^{3}$ que facilitan una interacción en tiempo real entre el streamer ${ }^{4}$ y su audiencia (Hilvert-Bruce et al., 2018).

La red social de videos en directo Twitch se ha establecido como el referente mundial de este nuevo tipo de contenidos audiovisuales (Gutiérrez y Cuartero, 2020). Esta plataforma surge en 2011 siendo parte de Justin.tv, cuyo propósito era transmitir partidas de videojuegos en directo explotando un

\footnotetext{
3 Término anglosajón que denomina a la retransmisión de contenidos en directo vía Internet.

${ }^{4}$ Creador de contenido que emite en una plataforma de video en directo.
} 
nuevo nicho de mercado por aquel entonces. No obstante, cuando la red social fue comprada por Amazon en 2014 empezó a convertirse paulatinamente en la plataforma predilecta para transmitir las competiciones más importantes de videojuegos (Burroughs y Rama, 2015).

Entre las características técnicas que hacen de Twitch un canal de comunicación diferenciado de otras redes sociales, destacan la jerarquización en torno a las opciones de participación en el chat, un bot configurable por el streamer, la opción de interpelación a otros usuarios y el uso de emoticonos específicos y exclusivos de la plataforma (emotes ${ }^{5}$ ).

Como resultado del incremento de audiencia en este formato audiovisual, otras compañías como Facebook, Microsoft o Google desplegaron sus propias plataformas de emisión de video en directo, como Facebook Gaming o Mixer. Sin embargo, ninguna de ellas tuvo el éxito de Twitch.

La retransmisión de videojuegos, categoría principal en este tipo de plataformas (Gandolfini, 2016), aúna dos medios diferentes: el medio difusor y los juegos que se transmiten. En el caso de los espectadores de televisión se ha considerado que se trata en gran medida de una actividad unidireccional (Ruiz, Cáceres y Brändle, 2010). En cambio, los videojuegos son valorados como una actividad multidireccional que requiere de la participación del usuario (Carrillo, 2015). Por lo tanto, la mezcla de estos dos medios de comunicación propicia un contexto con cierto grado de interacción, lo que implica que los usuarios tengan una experiencia más pasiva que al jugar ellos mismos a un videojuego, pero al mismo tiempo más activa que cuando consumen contenidos televisivos convencionales (Sjöblom y Hamari, 2017).

En Twitch existen dos tipos de roles: por un lado, los streamers, quienes transmiten su señal de video para compartir contenidos, y, por otro lado, los viewers o usuarios que ven el directo y pueden participar en él de diferentes formas (Hamilton, 2014). Los que transmiten los contenidos y los que ven las emisiones se relacionan a través un chat comentando las acciones que realiza el streamer.

Sobre estas bases se asienta un canal de comunicación en el que no solo el streamer tiene poder para comunicarse, sino que los espectadores pueden comunicarse con él y con otros usuarios de forma sincrónica a la emisión. En este ecosistema comunicativo, se produce una doble gratificación: por el lado del streamer, que recibe dinero a través de suscripciones y donaciones de sus

\footnotetext{
${ }^{5}$ Entrada de un usuario basada en un texto que indica que se está llevando a cabo una acción. A diferencia de los emoticonos, no son arte de texto, sino que describen la acción con palabras o imágenes.
} 
espectadores; y por el lado del espectador, que es premiado con la interacción con el streamer, el cual le puede contestar directamente (Gros et al., 2017). Esta forma de consumir y crear contenido facilita que haya muchos más prosumidores, término acuñado por Toffler en los años 80 y que hace referencia a un «tipo de público que opina, difunde y/o produce» (Lastra, 2016: 74), pues da pie a que no solo se vean contenidos, sino que los propios usuarios puedan producirlos.

Parte del éxito de Twitch radica en el propio funcionamiento de la plataforma, puesto que recurre al fenómeno de la co-presencia para establecer comunidades dentro de su audiencia, lo que posteriormente otras plataformas de streaming han imitado. La co-presencia digital es la situación en la que las personas están presentes en un espacio diferente a su ubicación física, aunque pueden ver al resto de espectadores que se encuentran en el mismo espacio virtual y socializar entre ellos (Diwanji et al., 2020). Se trata de un fenómeno distinto al que se produce en otras redes sociales o medios convencionales tales como YouTube o la televisión, en los cuales se puede ocasionar una situación de covisión, es decir, cuando más de un individuo consume el mismo tipo de contenido pudiendo estar o no en el mismo espacio físico, pero no puede interactuar con ellos al mismo tiempo (Pires de Sá, 2018). Por consiguiente, lo que hace especial a Twitch es que en ella se manifiestan ambos fenómenos, tanto el de la co-presencia como el de la co-visión.

A causa de ello, se han creado comunidades en las que el emisor del contenido interactúa con su audiencia de múltiples formas y genera en ellos un sentimiento de pertenencia a un grupo. Esa sensación de pertenecer a una comunidad virtual ha desembocado en que los usuarios de Twitch, como ocurre en otras redes sociales, desarrollen un argot determinado para comunicarse con el resto de los usuarios. La jerga de Twitch está caracterizada por incluir diversos memes ${ }^{6}$ de Internet, coloquialismos y terminología utilizada entre aficionados a los videojuegos. Asimismo, se utilizan mensajes cortos con pequeños iconos denominados emotes, los cuales dotan de nuevos significados a los mensajes de la comunidad y, para entenderlos, se requiere de un conocimiento previo de su cultura (Barbieri et al., 2017). Dentro de los emotes se pueden distinguir dos tipos: los creados por la propia plataforma y los que los streamers han diseñado exprofeso para su audiencia, distinguiéndose así del resto de usuarios de la plataforma (Oh et al., 2020).

\footnotetext{
${ }^{6}$ Unidad de información cultural que se transmite de una persona a otra o de una generación a la siguiente y que se caracteriza por su extensa difusión entre la población (Dawkins, 1976).
} 


\subsection{Plataformas VoD}

La penetración de las ofertas de plataformas de Video On Demand (VoD) ${ }^{7}$ registra unas cifras que hace que este fenómeno sea, sin duda, el gran caso de éxito de principios del siglo XXI «en un mundo digital abrumador» (García- Leiva, 2021: 111). El avance de la digitalización y la convergencia de medios exige que las empresas de radiodifusión de televisión ajusten su contenido a varias plataformas y canales de distribución. Internet, como medio de transporte convergente, está asumiendo cada vez más un papel central para los medios tradicionales (Mikos, 2016).

La construcción del mundo audiovisual en plataformas de VoD se considera como un modelo industrial más robusto porque representan el futuro del consumo diversificado de películas y de conseguir un marketing segmentado eficaz (Parvulescu, 2020). Además, permite a las producciones de poco presupuesto hacerse un hueco en el mercado que antes no podían permitirse (Sánchez-Maroto, 2018). Ello da lugar a distintos tipos de modelo de negocio dentro de las posibilidades de explotación a través de Internet, ya que las promociones son incontables y «la necesidad de establecer una comunicación entre el espectador y el canal es una constante» (Martínez y Mena, 2013: 9), cuyo objetivo es crear una fidelización que mantenga unas ratios de audiencia mínimamente estables.

A nivel global, la empresa de investigación de Mercado Motion Picture Assn asegura que durante 2020 los servicios de streaming han superado los 1000 millones de clientes. Bien es verdad que esto se debe al contexto en el que la población estuvo confinada durante varios meses en sus hogares por la pandemia de la COVID-19, pero el hecho es que una vez superada, los usuarios han continuado disfrutando de esos servicios casi en su misma medida. Entre 2019 y 2020 la audiencia de estas plataformas ha aumentado un $26 \%$ y, si tenemos en cuenta que de cada cliente existe más de un espectador - el consumo audiovisual es, en muchos casos, una acción social一, el número de usuarios es mucho mayor. El grupo de investigación de la Central Estadounidense de Inteligencia (la CIA) prevé para finales de 2022 que esa cifra llegue a los 7772 millones de personas en todo el planeta (Aranzubia y Gallego, 2021).

La aparición de plataformas como Disney+ ha acelerado este hecho y los productores de Hollywood ya incluyen en sus estrategias comerciales el hecho de estrenar antes en plataformas VoD sus filmes. No por nada, el gasto en entretenimiento en el hogar ha crecido un 23\% hasta 2020 llegando a los 68.800 millones de dólares en todo el mundo. Se ha demostrado que la llegada de las

\footnotetext{
7 Modo de distribución de contenido que facilita al espectador el consumo de un contenido específico dónde y cuándo quiera mediante una conexión a Internet.
} 
plataformas VoD no afecta gravemente al sector del cine ya que «las salas tuvieron un repunte en el número de espectadores, aunque la recaudación cae muy ligeramente» $\mathrm{y}$ «la variación de precio en la entrada a las salas de cine tampoco varía ni afecta al número de espectadores» (Muñoz-Serrano, 2020: 14).

Figura 1. Principales plataformas de VoD en España por número de suscriptores en 2020

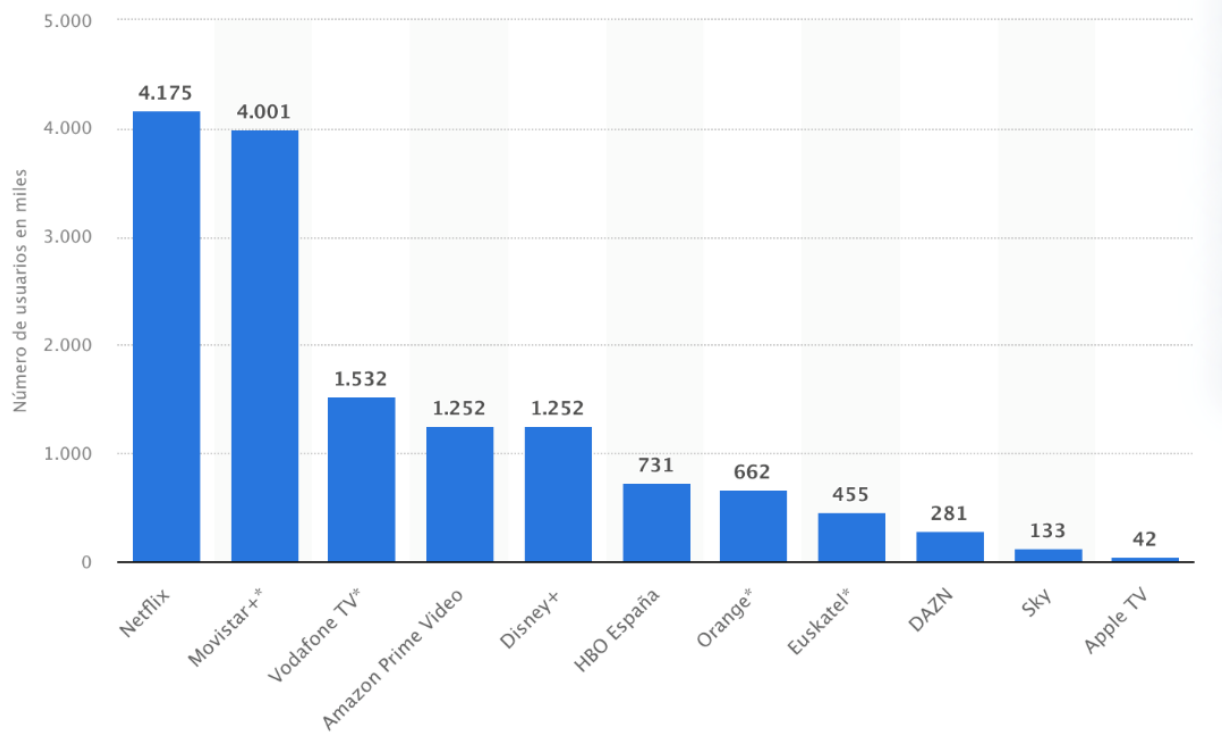

Fuente: statista.com.

En España, de esas plataformas que tienen presencia internacional y/o nacional, Netflix cuenta con más de 4 millones de clientes, un poco por encima de los que tiene Movistar+. Amazon Prime Video atesora los mismos usuarios que Disney+, 1.250 .000 personas, y HBO tiene 731.000 suscriptores.

Según la séptima oleada del Barómetro OTT publicado por GECA, el $62,3 \%$ de los usuarios encuestados declaran tener acceso a dos o más de estas plataformas, llegándose a ver que casi un $12 \%$ de todos ellos tiene cuenta en cinco o incluso ocho plataformas en el mismo momento. Alrededor de 9 de cada 10 encuestados se muestran dispuestos a renovar sus suscripciones, siendo Netflix $(92,8 \%)$, Prime Video $(92,1 \%)$ y Disney+ $(89,4 \%)$ las plataformas que presentan un mayor apego por parte de sus usuarios. 


\subsection{El auge de las Watch Parties}

Ante un contexto en el que las personas no han podido socializar con normalidad ni reunirse para consumir contenidos audiovisuales por la pandemia de la COVID-19, surgen iniciativas como la de Teleparty, una extensión para navegadores de Internet que da servicio a varias plataformas VoD como Netflix, o Watch Party, una funcionalidad exclusiva de Amazon Prime Video. En ambos servicios, a través de esta función, se facilita que el usuario pueda ver contenidos audiovisuales con quien quiera de forma telemática. Para ello, debe seleccionar dicha función y compartir el enlace que se genera con otras personas para visionar colectivamente y co-presenciar ese contenido. Es imprescindible que las personas invitadas posean una cuenta en la misma plataforma de VoD que el usuario que les invita. Una vez hecho eso, el contenido se sincroniza para todos los espectadores que lo ven al mismo tiempo, además de ofrecerles la opción de poder comentar en directo lo que están viendo.

En el caso del servicio de Watch Party de Prime Video se trata de una funcionalidad integrada en su propia plataforma. No obstante, esta iniciativa no se quedó reducida a la plataforma VoD de Amazon, sino que extendieron esta funcionalidad a su servicio de streaming Twitch.

En esta red social existen multitud de categorías, además de videojuegos, en las que aparecen Talk Shows, Just Chatting o Watch Parties, las cuales muestran otro tipo de contenido que posibilita mayor interacción entre el streamer y su público. En esta última, se utiliza el servicio de video grupal de Amazon para que el streamer pueda ver con su audiencia la serie o película que esté en el catálogo de Prime Video.

\subsection{Objetivos}

El objetivo general de esta investigación es identificar las características principales del consumo colectivo de contenido cinematográfico por parte de centennials a través del uso de la red social Twitch. De este planteamiento se derivan tres objetivos específicos:

1. Conocer los elementos y factores con los que se construye la experiencia del visionado colectivo de un largometraje cinematográfico por parte de una audiencia centennial.

2. Determinar el potencial de la plataforma social Twitch para la creación de hábitos y patrones de uso multipantalla, la articulación de roles y el desarrollo de procesos comunicativos.

3. Definir los rasgos comunes del contenido multidiscursivo (temas, referencias socioculturales y código expresivo) que se genera en una Watch Party. 
Estos objetivos conducen a formular tres bloques de preguntas que guían la investigación:

1. ¿Cómo es la experiencia de consumo colectivo, por parte de una audiencia centennial, de un contenido de ficción en la red social Twitch, en cuanto a la dinamización del streamer (streamers) y a la participación de la audiencia a través de comentarios sincronizados con el desarrollo de la película objeto de visionado?

2. ¿Qué recursos pone Twitch a disposición del streamer y de su audiencia y cómo inciden en los hábitos de experiencias de uso multipantalla, la articulación de roles y el desarrollo de procesos comunicativos?

3. ¿Qué caracteriza al contenido resultante de una Watch Party cinematográfica en cuanto a la obra de ficción visionada en comunidad y a lo que aportan las referencias, interpretaciones y códigos expresivos sociales, culturales y técnicos de los participantes?

\section{Metodología}

Se determina que la etnografía virtual sea la metodología básica para el diseño de la investigación, por su utilidad y oportunidad para el análisis de un fenómeno dentro de una red social en Internet, y por su potencial para aproximarse a la exploración de las relaciones que se establecen entre el usuario, el medio y su contexto en el entorno digital (Hine, 2015).

Los objetivos y preguntas de la investigación conducen a una tipología mixta de los instrumentos y enfoques metodológicos a emplear. Siguiendo a Bernal (2010) en su asociación del método cualitativo con la búsqueda de la comprensión de una situación social como un todo, teniendo en cuenta sus propiedades y sus dinámicas, se plantea un análisis inicial de carácter cuantitativo, que permita objetivar y sistematizar patrones de uso y consumo de la audiencia social. Esta descripción de la naturaleza singular de un fenómeno en desarrollo, con audiencias sociales de gran volumen como el de las Watch Parties en redes sociales, y con un amplio despliegue conversacional a través de mensajes de texto y gráficos, constituye el corpus del estudio que se aborda, así, desde una perspectiva cualitativa.

Para ello, se ha realizado un muestreo no probabilístico, que responde a criterios de conveniencia socioculturales, temporales y temáticos. Se ha efectuado una primera acotación a streamers hispanohablantes (en el estado de la cuestión se observó que la lengua era un factor cultural determinante, por encima del origen geográfico) con una audiencia centennial (identificada a través de las temáticas y los códigos expresivos predominantes en sus canales). Se ha dado prioridad a las emisiones con una mayor cercanía cronológica al 
transcurso de la etapa de análisis, para dotar a la investigación de una mayor actualidad y vigencia. Y se ha señalado como necesario el que las películas objeto de los visionados grupales se adscriban en distintos géneros con una diversidad mínima de audiencias potenciales. A partir de estos criterios, el objeto material de la investigación se ha acotado al estudio de caso de la categoría de Watch Parties del canal de Twitch del streamer español Lynx_Reviewer especializado en videojuegos y rol; uno de los pioneros en la celebración de visionados colectivos en español, con cifras sostenidas de asistencia masiva (con medias superiores a los 200 y picos en torno a los mil participantes), con una frecuencia de emisión significativa (una sesión por semana como mínimo) y cuya audiencia abarca a una población comprendida entre los 16 y los 30 años (según información proporcionada por el propio streamer). Para el análisis de las variables centrales, la muestra se ha concretado en la selección de tres visionados grupales de los más de 35 emitidos, durante los meses de abril y mayo de 2021 (fechas más cercanas a la etapa de análisis y por tanto de mayor actualidad), y asociados a tres géneros, temáticas y audiencias potenciales distintos. Con el paso del tiempo dichas emisiones son borradas, por lo que se acotó el análisis a un mes concreto al que el equipo investigador tuvo acceso al material para realizar el estudio.

Además de la recogida etnográfica de información durante los visionados en directo y el análisis de contenido en diferido de estas emisiones, para poder trabajar con el contenido de los comentarios realizados en el chat durante la proyección de las películas, ha sido necesario utilizar otros métodos como un análisis documental seleccionando informes y estadísticas fiables que aportasen datos de partida en el análisis. Asimismo, se han empleado diversas herramientas para la descarga y análisis de los datos a cuantificar. Con Twitch Downloader se han descargado en formato JSON los mensajes de los chats de las emisiones a analizar; utilizando Python se han transformado estos ficheros a un formato compatible con los programas de tratamiento de datos que se han empleado para trabajar con variables susceptibles de objetivación, cuantificación y sistematización estadísticas. Una vez recogida toda la muestra, se ha aplicado el conjunto de técnicas e instrumentos de investigación que configuran el estudio de caso y que se resumen a continuación:

Tabla 1. Estructura metodológica de las Watch Parties en Twitch

\begin{tabular}{|c|l|l|}
\hline \multicolumn{1}{|c|}{ Técnica } & \multicolumn{1}{|c|}{ Variables y unidades de análisis } & \multicolumn{1}{c|}{ Muestra } \\
\hline Análisis documental & Estadísticas de emisión & $\begin{array}{l}\text { Informes técnicos y de au- } \\
\text { diencia (Twitch y Amazon) } \\
\text { Otras fuentes estadísticas } \\
\text { Características técnicas de la interfaz } \\
\text { de Twitch }\end{array}$ \\
\hline
\end{tabular}




\begin{tabular}{|c|c|c|}
\hline $\begin{array}{l}\text { Entrevista } \\
\text { semiestructurada }\end{array}$ & $\begin{array}{l}\text { Configuración de la emisión } \\
\text { Características y patrones de con- } \\
\text { sumo de la emisión } \\
\text { Estrategias de creación de contenidos } \\
\text { y dinamización }\end{array}$ & $\begin{array}{l}\text { Respuestas del streamer a } \\
\text { las preguntas formuladas: } \\
\text { origen de su participación } \\
\text { en redes sociales; funciona- } \\
\text { miento del canal de Twitch; } \\
\text { estrategias para fomentar } \\
\text { la interacción de la audien- } \\
\text { cia con el creador y entre } \\
\text { espectadores; justificación } \\
\text { de la selección de películas; } \\
\text { valoración de la innovación } \\
\text { en comunicación de las } \\
\text { emisiones; contraste con } \\
\text { los medios tradicionales y } \\
\text { valoración de la relación de } \\
\text { esto con las audiencias del } \\
\text { canal }\end{array}$ \\
\hline $\begin{array}{l}\text { Etnografía virtual } \\
\text { y Análisis de } \\
\text { contenido }\end{array}$ & $\begin{array}{l}\text { Intervenciones del streamer (relacio- } \\
\text { nadas/no relacionadas directamente } \\
\text { con la película) } \\
\text { Efectos de la dinamización por el } \\
\text { streamer en la audiencia } \\
\text { Tasa de actividad del chat } \\
\text { Interpelaciones al streamer } \\
\text { Interpelaciones entre espectadores } \\
\text { Uso de emoticonos (propios del } \\
\text { creador/otros) } \\
\text { Peso y función expresiva de los } \\
\text { emoticonos en la conversación } \\
\text { Comentarios totales realizados en } \\
\text { el chat } \\
\text { Comentarios del chat relacionados di- } \\
\text { rectamente con la película (número, } \\
\text { peso y categorías abordadas) } \\
\text { Comentarios del chat no relacionados } \\
\text { directamente con la película } \\
\text { (número, peso y temas sociales y } \\
\text { referencias culturales abordados) } \\
\text { Uso de jerga }\end{array}$ & $\begin{array}{l}\text { Seguimiento en directo y } \\
\text { en diferido de las emisiones } \\
\text { Contenido audiovisual de } \\
\text { las películas proyectadas } \\
\text { Contenido de las } 337 \\
\text { intervenciones del streamer } \\
\text { a través de su canal (video } \\
\text { y audio) } \\
\text { Contenido de los } 5860 \\
\text { comentarios (texto y } \\
\text { emotes) de los chats }\end{array}$ \\
\hline
\end{tabular}

Fuente: elaboración propia. 


\section{Resultados}

Los distintos análisis realizados para abordar el estudio de caso del visionado en grupo de películas en el canal de Twitch de Lynx_Reviewer permiten alcanzar el objetivo general de la investigación: los resultados que se presentan a continuación reflejan las características fundamentales del consumo colectivo de contenido audiovisual tradicional en esta red social por los centennials.

Como recogen las estadísticas de TwitchTracker, una Watch Party de Lynx_Reviewer reúne simultáneamente a una media de 292 espectadores, dato que en algún momento de la emisión puede multiplicarse hasta alcanzar un pico máximo de 941 . Son datos que cuadruplican la media en resultados de audiencia globales de otros streamers de la categoría, marcados en mayo en un promedio de 61 espectadores por canal. Otros streamers con un mayor número de seguidores (aunque con el factor corrector de que responden a una frecuencia de emisión menor), como Alexelcapo, hacen crecer esas cifras de audiencia hasta una media de 5480 espectadores y un pico máximo de 6613 en visionado simultáneo.

La experiencia en una Watch Party de Twitch se desarrolla a través de una interfaz que combina dos pantallas y tres zonas, y que cada usuario puede dimensionar y visibilizar en función de sus preferencias o posibilidades de sincronización: la destinada a la película; la que emite el streamer (con voz e imagen); y el chat de texto. Esta configuración del objeto de estudio justifica el carácter mixto del análisis realizado, que alterna las respuestas a la entrevista al streamer, con la información cualitativa obtenida en la observación holística de los visionados grupales; y que se completa con los datos cuantitativos del análisis del contenido de los mensajes del streamer y de los participantes en el chat, que se resumen en la siguiente tabla:

Tabla 2. Análisis del contenido de la muestra

\begin{tabular}{|l|r|r|r|r|r|r|r|r|r|r|}
\hline & $\begin{array}{l}\text { TO- } \\
\text { TAL }\end{array}$ & $\begin{array}{c}\text { ME- } \\
\text { DIA }\end{array}$ & $\%$ & CREED & $\%$ & $\begin{array}{c}\text { BIRD- } \\
\text { MAN }\end{array}$ & $\%$ & $\begin{array}{c}\text { SPI- } \\
\text { DER- } \\
\text { MAN }\end{array}$ & $\%$ \\
\hline \begin{tabular}{l} 
INFORMACIÓN GENERAL \\
\hline $\begin{array}{l}\text { Espectadores } \\
\text { (media) }\end{array}$
\end{tabular} & 800 & 267 & & 265 & & 152 & & 383 & \\
\hline $\begin{array}{l}\text { Mensajes del } \\
\text { chat }\end{array}$ & 5860 & 1953 & & 1339 & & 1264 & & 3257 & \\
\hline $\begin{array}{l}\text { Tasa de } \\
\text { actividad } \\
\text { (mensajes/ } \\
\text { espectador) }\end{array}$ & - & 7,33 & & 5,05 & & 8,32 & & 8,50 & \\
\hline
\end{tabular}




\begin{tabular}{|c|c|c|c|c|c|c|c|c|c|}
\hline \multicolumn{10}{|l|}{ STREAMER } \\
\hline $\begin{array}{l}\text { Intervencio- } \\
\text { nes totales }\end{array}$ & 337 & 112 & $5,8 \%$ & 78 & $6 \%$ & 120 & $9 \%$ & 124 & $4 \%$ \\
\hline $\begin{array}{l}\text { Intervencio- } \\
\text { nes sobre la } \\
\text { película }\end{array}$ & 215 & 72 & $3,7 \%$ & 47 & $4 \%$ & 57 & $5 \%$ & 103 & $3 \%$ \\
\hline $\begin{array}{l}\text { Intervencio- } \\
\text { nes ajenas a } \\
\text { la película }\end{array}$ & 122 & 41 & $2,1 \%$ & 31 & $2 \%$ & 63 & $5 \%$ & 21 & $0,6 \%$ \\
\hline \multicolumn{10}{|c|}{ ACTIVIDAD DEL CHAT } \\
\hline $\begin{array}{l}\text { Interpelacio- } \\
\text { nes de es- } \\
\text { pectadores } \\
\text { al streamer }\end{array}$ & 255 & 85 & $4,4 \%$ & 65 & $5 \%$ & 65 & $5 \%$ & 115 & $4 \%$ \\
\hline $\begin{array}{l}\text { Interpelacio- } \\
\text { nes entre } \\
\text { espectado- } \\
\text { res }\end{array}$ & 480 & 160 & $8,2 \%$ & 120 & $9 \%$ & 112 & $9 \%$ & 230 & $7 \%$ \\
\hline $\begin{array}{l}\text { Uso total de } \\
\text { emotes }\end{array}$ & 1237 & 412 & $21,1 \%$ & 342 & $25 \%$ & 239 & $19 \%$ & 612 & $19 \%$ \\
\hline $\begin{array}{l}\text { Emotes } \\
\text { propios del } \\
\text { creador }\end{array}$ & 120 & 38 & $2,0 \%$ & 38 & $3 \%$ & 38 & $3 \%$ & 38 & $1 \%$ \\
\hline $\begin{array}{l}\text { Otros } \\
\text { emotes }\end{array}$ & 1118 & 373 & $19,1 \%$ & 304 & $23 \%$ & 201 & $16 \%$ & 574 & $18 \%$ \\
\hline $\begin{array}{l}\text { Comentarios } \\
\text { sobre la } \\
\text { película }\end{array}$ & 1533 & 511 & $26,2 \%$ & 537 & $40 \%$ & 548 & $43 \%$ & 365 & $11 \%$ \\
\hline $\begin{array}{l}\text { Comentarios } \\
\text { ajenos a la } \\
\text { película }\end{array}$ & 4492 & 1497 & $76,6 \%$ & 802 & $60 \%$ & 716 & $57 \%$ & 2857 & $88 \%$ \\
\hline
\end{tabular}

Fuente: elaboración propia.

\subsection{Patrones de emisión, dinamización y participación en las Watch Parties de Twitch}

Según las estadísticas globales de Twitch Tracker, los fines de semana se presenta un aumento del $60 \%$ de espectadores y, además, en esos días también se hacen un $50 \%$ más de Watch Parties. Este incremento, tanto en producción como consumo, se debe a un aumento de tiempo libre por parte de la audiencia.

El emisor decide qué película va a visionar con su audiencia. Este procedimiento se puede hacer de forma unilateral, es decir, por el interés particular del streamer por ver una película concreta, o de forma comunitaria, esto es, mediante peticiones de los seguidores, las cuales el emisor recoge en una encuesta y se elige la más votada. Sin embargo, Lynx_Reviewer señala «hay que escoger 
las películas adecuadas para que la audiencia interactúe, si selecciono una película muy dramática o intensa es difícil que la gente participe».

El emisor comienza a transmitir y junto a su audiencia ajusta los parámetros necesarios para cerciorarse de que el visionado colectivo de la película está sincronizado con el de su audiencia. Para ello, dispone de un contador de tiempo con el que las personas que no poseen Prime Video puedan visionar en otras plataformas ese mismo contenido simultáneamente (Figura 2). Durante el análisis de las Watch Parties examinadas se ha observado que los primeros minutos de la emisión de la película hay numerosos comentarios preguntando sobre cómo sincronizar su visionado con el del streamer. En esos momentos, no solo el emisor resuelve dudas, sino que entre los propios espectadores se ayudan para disfrutar de la experiencia colectiva.

Figura 2. Captura de pantalla de Watch Party de Birdman

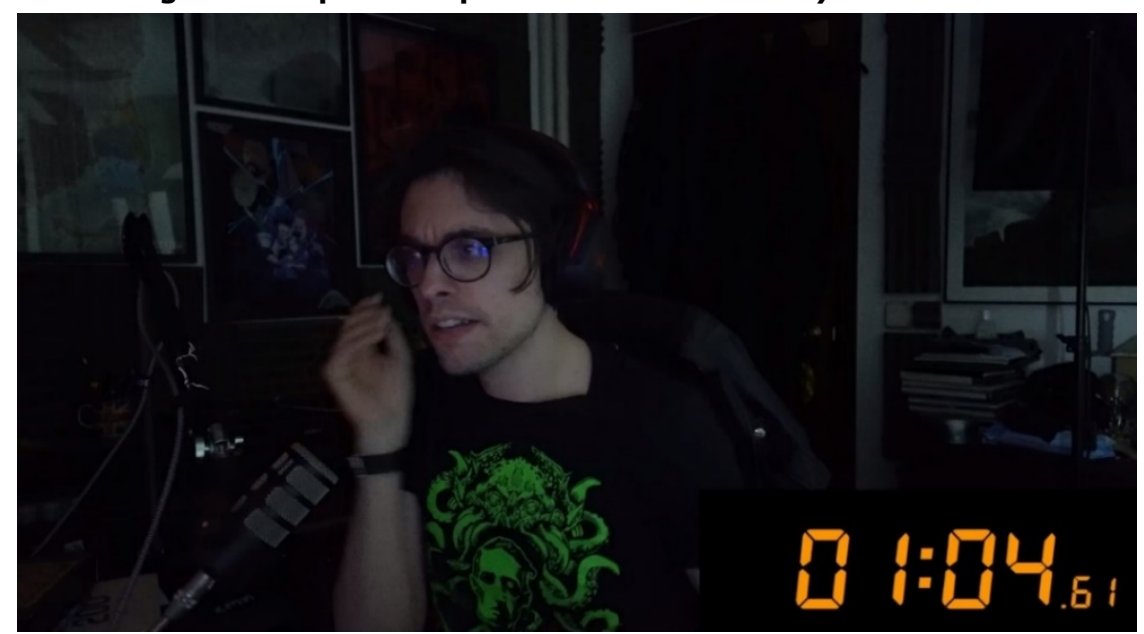

Fuente: twitch.tv/lynx_reviewer.

En relación con la dinamización del chat de la emisión, en palabras de Lynx_Reviewer, hace comentarios sobre lo que están viendo, plantea preguntas de actualidad relacionadas con el contenido o establece dinámicas basadas en una interacción en tono humorístico para promover la participación y la distensión entre su audiencia. Esta dinamización del chat se traslada a las Watch Parties para comentar o preguntar cosas sobre la película. Según Lynx_Reviewer, «hay gente a la que le gusta hablar del reparto o comentar detalles de la película. Cuando alguien hace ese comentario, lo leo para destacarlo sobre los demás para que sigan escribiendo comentarios así». 
Al analizar estas estrategias de dinamización con las muestras recogidas, a pesar de las diferencias entre una película y otra, si se promedian los datos se muestra una tendencia que se repite en los distintos visionados colectivos. Desde esta aproximación se observa que la mayor parte del peso comunicativo recae en los espectadores, con un promedio de 2018 interacciones en las muestras analizadas. En este sentido, si se observa el número de interacciones en la Figura 3, se hace evidente que los usuarios interactuaron más durante el visionado colectivo haciendo comentarios no relativos a la película, mientras que el streamer por promedio realizó más comentarios sobre las películas.

Figura 3. Dinamización y contenido de las Watch Parties

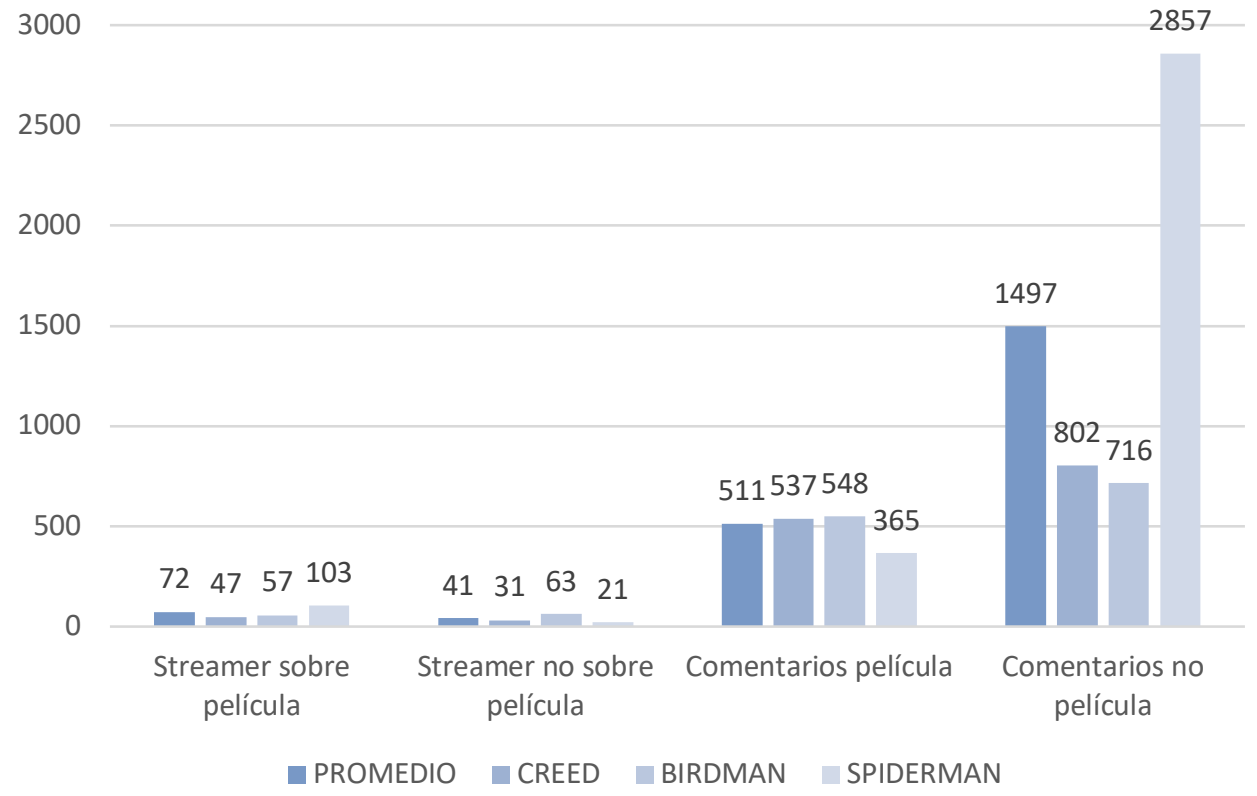

Fuente: elaboración propia.

Al desagregar la Figura 3, cabe destacar la tasa de actividad de cada uno de los directos analizados. Esta tasa es el resultado de dividir el número de comentarios totales entre el número de espectadores medios por cada emisión analizada. Tal y como se puede observar en la Figura 4, tanto el visionado colectivo de Birdman como el de Spiderman: Into the Spider Verse obtuvieron ratios de actividad elevados, con una tasa de 8,32 en el primer caso y de 8,5 en el segundo caso. Sin embargo, la tasa de actividad de Creed fue del 5,05. 
Esta diferencia entre las tasas se debe al tiempo de emisión del directo. En el caso de Birdman la emisión duró 2 horas y 47 minutos, en Spiderman: Into the Spider Verse la duración fue de 2 horas y 18 minutos y en Creed la duración fue de 5 horas y 49 minutos. En consecuencia, el factor atención con el paso de las horas se va diluyendo $y$, por consiguiente, repercute en los niveles de audiencia y su grado de participación. Asimismo, también es importante señalar el contenido que se emitió previamente al visionado colectivo, ya que en Creed antes se emitió contenido sobre videojuegos, por lo que al cambiar de contenido parte de su público se fue al no interesarle la temática. Sin embargo, con los otros dos visionados colectivos, la audiencia se mantuvo estable y hubo un mayor nivel de participación, pues dichos directos tenían una temática ajustada a la actividad de la visualización colectiva.

Figura 4. Tasa de actividad de los espectadores durante el visionado colectivo

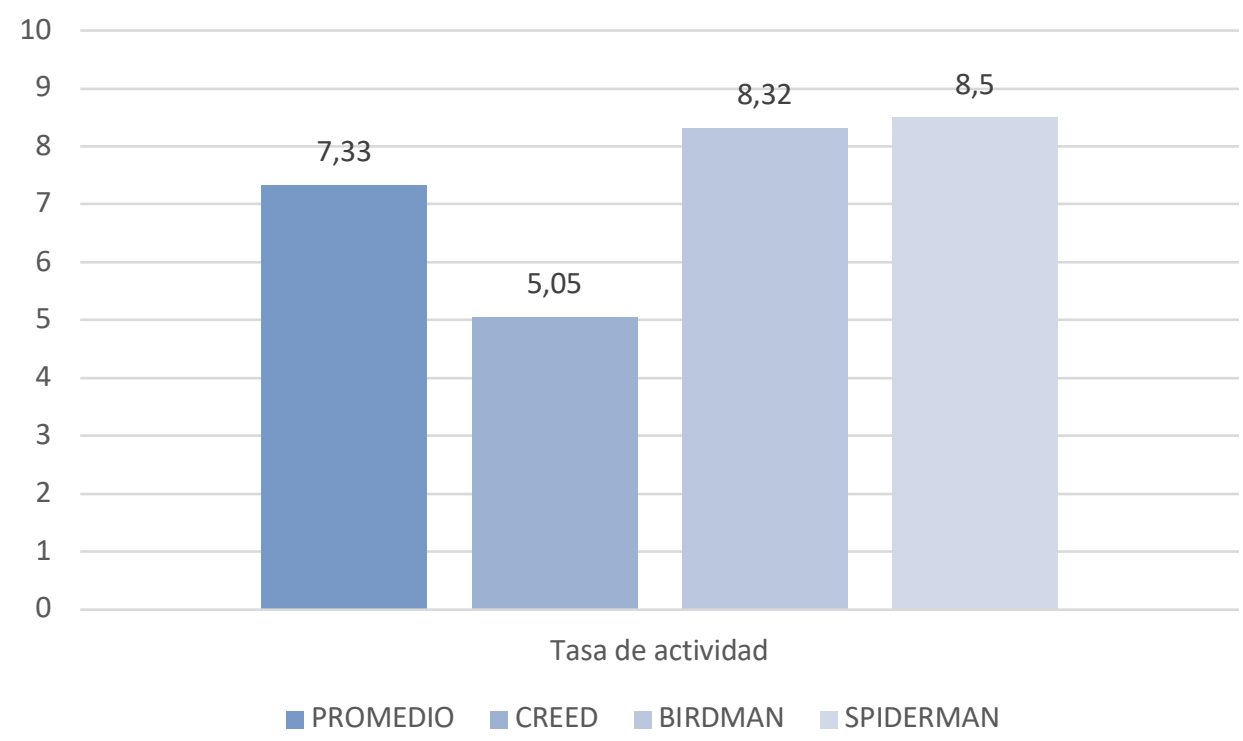

Fuente: elaboración propia.

No obstante, dada la variabilidad de audiencias en este tipo de eventos, se ha calculado una tasa de actividad promedio del 7,33, lo que implica que, en líneas generales, a pesar de unos niveles de audiencia inferiores con respecto a otros contenidos emitidos por el streamer, en este caso concreto la audiencia está comprometida con el contenido, pues participa de forma activa. 
Figura 5. Actividad de los usuarios en el chat durante las Watch Parties

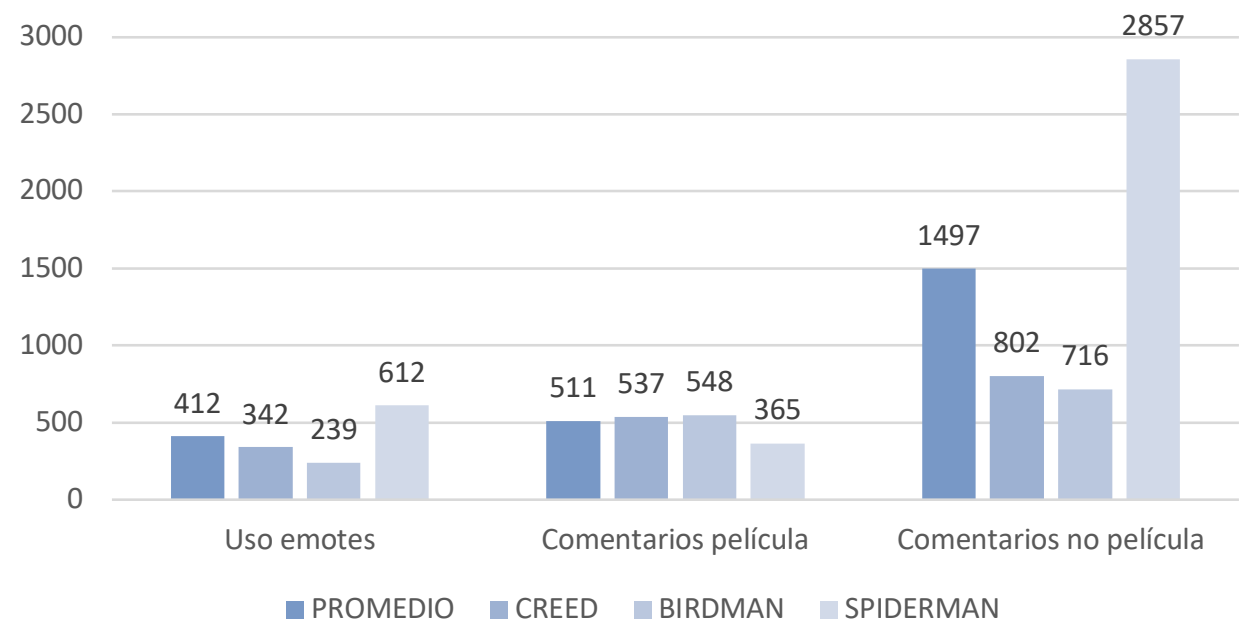

Fuente: elaboración propia.

Atendiendo a la Figura 5, la retransmisión de Spiderman: Into the Spider Verse fue en la que más emotes se utilizaron y más comentarios obtuvo la película (3222). No obstante, a pesar de un mayor volumen de comentarios se mantiene la proporcionalidad vista en el promedio. Así pues, de esta gráfica se obtiene que en los tres visionados colectivos casi un tercio de los mensajes del chat fueron emotes y, especialmente, se observa que hay más comentarios no referidos a la película que sobre ella.

\subsection{Usos y actividades comunicativas de la interfaz de Twitch}

Con el fin de determinar el potencial social de Twitch para el desarrollo de procesos de uso, consumo y comunicación, se ha abordado el estudio de las formas de interacción con el contenido, que dependen de factores externos a Twitch como el uso multipantalla, pero también de factores internos. Entre estos últimos, el más importante es la articulación de roles dentro de una comunidad de Twitch. En estas comunidades, los usuarios están clasificados en suscriptores y seguidores; los primeros pagan una cuota mensual al streamer y obtienen ventajas sobre los demás, como por ejemplo el uso exclusivo de emotes, mientras que los segundos no tienen acceso a esas ventajas, pero también pueden interactuar dentro del chat.

La interpelación entre sujetos en Twitch es la intención que tiene un usuario de interactuar directamente con el emisor o con otros usuarios del 
directo. Para realizar una interpelación, el usuario puede o bien lanzar un mensaje en general con el nombre del usuario al que se refiere, lo que denominamos interpelación indirecta, o bien puede usar «@» seguido del nombre a quien quiere interpelar y escribir un texto, esto es, interpelación directa.

Con respecto a las interpelaciones indirectas, gran parte de ellas se refieren a menciones al propio streamer al cual acortan su nombre llamándole Lynx o incluso traduciendo su nombre a Lince como un apelativo cercano o cariñoso, dicho nombre se tuvo en cuenta al cuantificar los datos. En estos chats, en los que la afluencia de mensajes no es tan elevada, el streamer puede ver esos mensajes a conveniencia gracias a una herramienta para streamers de Twitch, en la que navegar fácilmente por el chat.

Las interpelaciones más frecuentes en los chats son las directas a través del uso de «@» para referirse a otra persona tal y como mostramos en la Figura 6. En esta modalidad se puede observar que el promedio de interpelaciones al streamer es de 85 por visionado colectivo, manteniendo un porcentaje similar en todas las emisiones, un 4,4\% del total de mensajes del chat. Este número de interpelaciones aumenta en las realizadas entre espectadores, siendo la media 160 y con un porcentaje de 8,2\% del total de mensajes del chat.

Figura 6. Interpelaciones que realiza la audiencia

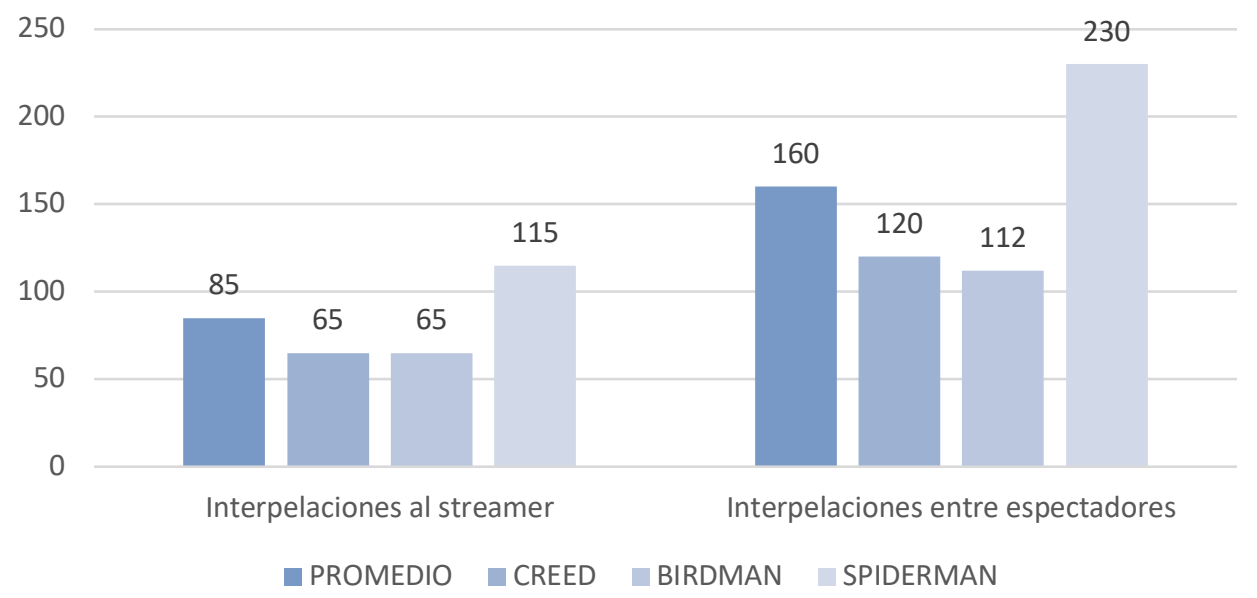

Fuente: elaboración propia.

Si con la interpelación se establece la direccionalidad del mensaje entre emisor y receptores, con el emote se dota al mensaje de emoción a través del simbolismo, ya que aporta una mayor profundidad significativa al mensaje (Figura 7). 
Figura 7. Captura de pantalla de Watch Party de Spiderman

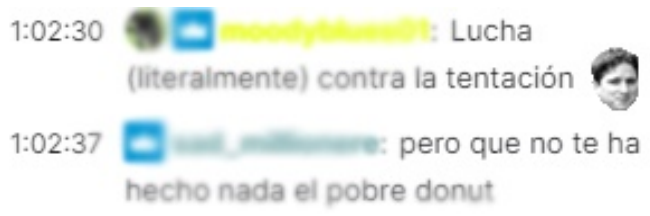

Fuente: twitch.tv/lynx_reviewer.

Por ejemplo, un usuario que usa el emote «Kappa» al dirigirse a otro usuario dota de ironía su mensaje. En la Figura 7 se observa cómo se interpela al streamer irónicamente para que se coma un donut. Con este tipo de interacción mediante emote cabe destacar que si no se conoce el significado de dicho símbolo entonces el mensaje pierde matices.

En el caso que nos ocupa, se ha querido saber el porcentaje de comentarios totales usados en el chat comparado con los emotes propios del streamer y con otros emotes creados por la comunidad de Twitch. Tal y como puede verse en la Figura 8, en el total de comentarios del chat se usa una media de $412 \mathrm{emo}$ tes generales $(21,1 \%$ del total de emotes que se usan) frente al uso promedio de 38 emotes del propio creador (10\%) en las tres Watch Parties estudiadas.

Figura 8. Uso de emotes creados por el streamer y empleados por los usuarios

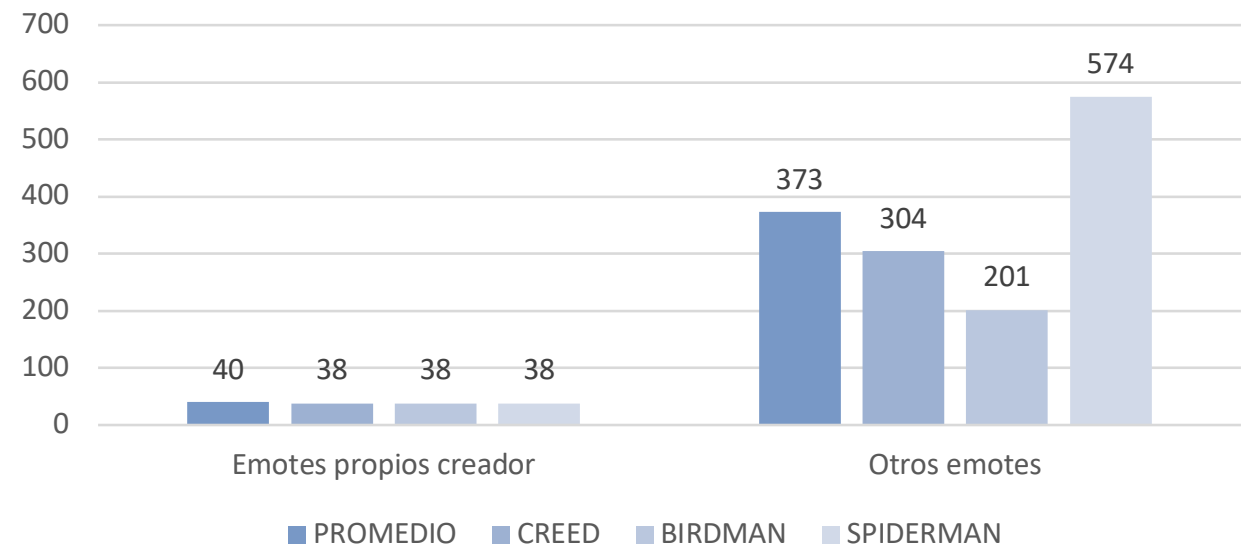

Fuente: elaboración propia.

En detalle, se usa una media de unos 35 emotes de llanto o tristeza (suponen el 10\% del total de emotes que se usan), siendo «LynxRevLLoro» (del propio creador), «biblethump» y «:(» los más significativos. Cabe destacar que el uso de estos emotes que simbolizan tristeza se emplea como respuesta ante un 
hecho dramático de la película, como en Creed cuando un personaje es diagnosticado con cáncer o en Spiderman cuando un personaje muere.

Sin embargo, los sentimientos más alegres son más referenciados. Así, se usa una media de unos 209 emotes de carcajada o sonrisa (suponen el $51 \%$ del total de emotes que se usan), siendo LUL el más utilizado, seguido de «XD» $\mathrm{y}$, en menor medida, LOL o KEKW. El mundo virtual es un espacio de compartición, pero lo que suelen proyectar sus usuarios son aspectos positivos de cada uno. Lo negativo (más en un chat) no suele ser recibido con gusto por los participantes.

\subsection{La Watch Party de Twitch como producto de consumo audiovisual}

$\mathrm{Al}$ analizar la muestra se observa que se repite un patrón en todos los visionados colectivos. Antes de empezar la emisión del visionado colectivo, Lynx_Reviewer hace una sección previa hablando con su audiencia de temas personales. En ese momento de la retransmisión expone un rótulo animado para avisar a su audiencia de que está en directo. Esa estrategia repercute en la cantidad de personas que se unen al directo: en el caso de Spiderman al inicio se conectaron 300 personas y esa audiencia fue creciendo hasta tener más de 1000 usuarios simultáneos.

Una vez hecho eso, se dispone a emitir la película y explica cómo sincronizar la señal su directo con la de los espectadores; a raíz de ello surgen comentarios de índole técnica preguntando sobre estos aspectos. Cuando estas cuestiones técnicas quedan resueltas bien por el streamer o bien por otros usuarios, la audiencia comienza a hacer referencias directas, un promedio de 511, o indirectas a la película, un 30\% del promedio de 1497 comentarios que no están vinculados con la película (Figura 3).

En los comentarios directos al filme se hace referencia a aspectos técnicos del largometraje como los planos secuencia de los combates de boxeo en Creed o aspectos de la animación en Spiderman, pero también se habla del reparto de la película como en Birdman o su banda sonora. No obstante, los comentarios más abundantes son los no referidos a las películas, aunque un tercio hacen una referencia indirecta a ellas, ya que con el visionado del largometraje surgen temas que el streamer e incluso los propios espectadores sacan a colación como el cáncer o su opinión del boxeo en Creed, el acoso laboral en Birdman o en qué cómics se basa la película de Spiderman. Sin embargo, lo más destacable en esta categoría de comentarios son aquellos que se desvían de la película, pero que se originan a través de ella, como al hablar de ciertas situaciones en Creed cuando el protagonista lleva una mascarilla, lo que desata varias referencias a la COVID-19 o en Birdman cuando el teatro está lleno y se habla de la época prepandemia. 
Se aprecia que estos comentarios van parejos al desarrollo de la trama de la película y según la película que se esté retransmitiendo cambia la temática de los comentarios, tanto de los directos como de los indirectos. En ellos se alude a referencias culturales según las escenas visionadas. Asimismo, según la película también se determina la categoría de emotes que se utilizan, siendo reseñable el uso del emote «BONK», que hace alusión a un mazo de juez que dicta sentencia, para censurar una actitud en la película de Birdman, o el continuo uso de emotes de connotación triste en Spiderman y Creed cuando suceden hechos dramáticos en ambas cintas.

Precisamente, lo más característico y enriquecedor del discurso en redes sociales es el empleo de códigos expresivos sociales y culturales propios. En el análisis de la muestra, se han observado múltiples referencias a videojuegos y cómics, contenidos que consumen e interesan a la audiencia de Lynx_Reviewer. Así, en Spiderman se establece un debate sobre qué es canon ${ }^{8}$ y qué no dentro de la película. En Creed aparecen referencias a términos de videojuegos como «baitear», término popularizado en el videojuego League of Legends. En Spiderman y Creed aparece el emote «biblethump» para expresar tristeza. El diseño de este emote pertenece a un personaje del videojuego The Biding of Isaac que aparece llorando durante el juego.

También como parte del acervo cultural relacionado con la plataforma aparecen los usos del lenguaje relacionados con la edad y la segmentación cultural de estos. En el caso de Creed, se usó la jerga común en las redes sociales y muy frecuente en memes de Internet, como «está mamadísimo» para referirse a lo fuerte que es un personaje. Además, se usaron otras expresiones como «modo sexo on» aludiendo a las escenas en las que los personajes estaban en situaciones íntimas. En Spiderman utilizan el término de «chad» proveniente de un meme de Internet que expresa cuando un hombre es sexualmente exitoso. Por tanto, se valora que existe un marcado componente sexual y humorístico a la hora de emplear la jerga propia en Twitch, la cual simula una experiencia distendida dentro de un grupo de amigos.

Por último, al finalizar el visionado de la película, durante los últimos minutos del directo, la audiencia suele comentar aspectos generales de lo que les ha parecido el largometraje, habla de temas paralelos a la cinta y propone futuros visionados.

\footnotetext{
8 Todo contenido certificado como oficial por el propietario de la obra. En ficción un contenido es canónico cuando se circunscribe adecuadamente al contexto del universo de la obra.
} 


\section{Discusión}

Uno de los principales retos de esta investigación es el de explorar las características específicas del consumo de un contenido audiovisual tradicional, unidireccional y abierto a todo tipo de generaciones, aunque consumido especialmente por centennials, a través de un medio que, como en el caso de Twitch, sí tiene un componente experiencial propio de estos grupos de edad.

La etnografía virtual, que ha guiado el trabajo de investigación permitiendo la identificación y definición de los rasgos característicos del caso analizado, se presenta como una metodología eficiente para abordar el fenómeno de los visionados colectivos de largometrajes a través del uso de la red social Twitch por parte de centennials en la actualidad.

El recurso al estudio de caso, con la consiguiente selección de un muestreo no probabilístico de conveniencia, hace que los logros de esta investigación se enfoquen en la aproximación a un fenómeno emergente, con los límites a la representatividad y a la extrapolación que ello conlleva. Esta opción metodológica junto con la constatación mediante la exploración del estado de la cuestión de que se trabajando con un caso paradigmático, un streamer representativo del entorno hispanohablante que emite con frecuencia un formato específico para visionar colectivamente películas, es la que ha permitido llegar a las múltiples aristas de un sistema complejo y diverso, a las raíces de un árbol de relaciones dinámico y espontáneo.

La sistematización, objetivación y cuantificación que aporta el análisis de contenido, acompañadas de la triangulación y la confirmación que ofrecen la etnografía virtual, el análisis de contenido y la entrevista semiestructurada al streamer, transforman lo que podría ser una limitación en una aportación estimable al ámbito de conocimiento: la propuesta de un modelo de análisis, mediante la selección de bases y raíces comunes, que pueda ser valorado para su aplicación a otros usos, contenidos y audiencias de Twitch, una red social en crecimiento exponencial y cuyo tratamiento como objeto de estudio (según se ha expuesto en la elaboración del estado de la cuestión) apenas ha comenzado su andadura con acercamientos poco profundos.

\section{Conclusiones}

La experiencia de visionado colectivo de cine a través de Watch Parties en Twitch se construye a partir de una dinamización constante del streamer y de la participación masiva de la audiencia a través de comentarios sincronizados con el desarrollo de la película proyectada.

El papel del streamer es clave en el desarrollo de una actividad que no es el ámbito para el que nació esta plataforma social ni para la explotación del 
canal, ni para sus seguidores o consumidores habituales de Twitch, original y principalmente reunidos en torno al mundo de los videojuegos. Sus estrategias se centran en configurar una emisión capaz de atraer y mantener audiencia en el canal; en formular cuestiones de actualidad para que la conversación generada sea abundante; en recompensar determinados comentarios para dotar al conjunto de una mínima coherencia narrativa y evitar una ramificación excesiva; y en articular y facilitar un discurso cargado de elementos socioculturales y generacionales, para que el contenido resultante tenga un valor diferencial en lo temático, y de pertenencia en lo referencial y expresivo, actualizando lo apuntado por la teoría de la identidad social (Tajfel y Turner, 1986).

La jerarquización de la participación durante las emisiones en directo produce una asignación de roles que se traduce en una mayor atención por parte del streamer y unas diferencias en la capacidad expresiva entre quienes pueden utilizar y crear emotes exclusivos e incluso moderar, y quienes cuentan con los recursos mínimos para la participación en el chat de texto.

La posibilidad de lanzar mensajes contextuales a través del bot del streamer y las opciones de mención a otros usuarios (mediante «@») son el reflejo de la importancia que tiene en el conjunto de la experiencia el facilitar una participación coral entre espectadores presentes en un mismo espacio virtual.

En cuanto a los emotes, intensivamente utilizados por los participantes por su capacidad para hacer más expresivas las acciones, son grandes condicionantes a la hora de mostrar que se está participando activamente en un canal de texto con un volumen y una velocidad de emisión de mensajes extraordinariamente altos. En el caso estudiado, el ritmo de la participación en el chat muestra un promedio de uso de un emote cada 18 segundos, dentro de una frecuencia media de emisión de un mensaje cada 4 segundos. Estas cifras dibujan una característica clave del fenómeno del visionado colectivo: que el chat no es un canal de contenidos intermitentes o complementarios, sino que se integra plena y prácticamente en el mismo plano que la película en el conjunto de la experiencia narrativa. Son datos que abren, al tiempo, una vía de investigación futura sobre si una frecuencia tan alta de emisión de mensajes puede obstaculizar la interacción o mermar la eficiencia comunicativa. Por lo observado en el canal de Twitch de Lynx_Reviewer hay una regulación tácita de la interacción, de manera que quienes participan con mensajes en el chat suponen algo menos de la mitad de los asistentes: ello permite mantener una frecuencia de gran velocidad pero no atropellada, aunque determinando una experiencia en la que algo más de la mitad de la audiencia ejerce un consumo pasivo de los contenidos.

Como contenido, las películas (que son el objeto de una Watch Party) se enriquecen con su consumo colectivo a través de Twitch. El cine, mediante el 
soporte técnico de la red social, pasa de ser un medio unidireccional a un medio bidireccional, en el que los espectadores pueden interactuar con el emisor de la sesión y con otros usuarios presentes en el chat. En este espacio intercambian referencias e interpretaciones del producto audiovisual con sus propios códigos expresivos sociales y culturales. La mayoría de los comentarios de los participantes versan sobre diversos aspectos más allá de la película, que acaba jugando un papel complementario e instrumental. Una Watch Party no deja de ser una reunión virtual de cientos de personas agrupadas en torno a un objetivo común, en este caso el partir de los estímulos de una obra cinematográfica para entablar y generar conversación sobre otros temas.

Como medio, la Watch Party establece un formato caracterizado por el despliegue de expresiones utilizadas en los ámbitos de los chats de Internet, las redes sociales y los videojuegos; y recursos asociados a esos entornos, como los emoticonos que aportan matices nuevos al visionado de películas. El lenguaje es, a un tiempo, elemento diferenciador del contenido y aglutinador de sus cocreadores: porque si la experiencia se origina en la motivación por compartir el consumo de una película, se desarrolla en mayor medida por la libertad que los espectadores sienten que tienen para expresarse, sabiendo que todos los que participan van a entenderles y a empatizar con ellos.

El alcance de estas conclusiones invita a la realización de futuras investigaciones. El modelo metodológico empleado es eficiente para abordar el estudio de otros canales de Twitch que emiten Watch Parties. No obstante, este análisis también se puede extrapolar al consumo audiovisual de otro tipo de eventos dentro de la plataforma como pueden ser retransmisiones deportivas como el combate del año, la velada de boxeo organizada por Ibai Llanos, la cual según Twitch Tracker tuvo una audiencia media de 1.087.208 de espectadores y un pico de 1.538.645 de audiencia. Además, no solo es extrapolable a otros contenidos de Twitch sino que también se puede emplear para analizar otros fenómenos de uso y consumo audiovisual en plataformas de streaming como YouTube o Facebook Gaming, en los que se interactúa entre emisor y público mediante una interfaz similar a la que ofrece Twitch.

\section{Referencias bibliográficas}

ARANZUBIA, A., y GALLEGO, J.I. (2021). El cine español en el catálogo de Netflix: una aproximación desde la perspectiva de la diversidad. Comunicación y Sociedad, 1-21 doi.org/10.32870/cys.v2021.8030

AvEndaño, S. (5 de julio de 2020). Prime Video lanza 'Watch Party' para ver películas y series con amigos a distancia. Unocero. https://bit.ly/3tGIQcG

BARBIERI, F., ESPINOSA-ANKE, L., BALLESTEROS, M., y SAGGION, H. (2017). Towards the understanding of gaming audiences by modeling twitch emotes. 
In Third Workshop on Noisy User-generated Text (W-NUT 2017), 11-20. Denmark: ACL (Association for Computational Linguistics). http://hdl.handle.net/10230/33289

BERNAL, C.A. (2010). Metodología de la Investigación. México: Pearson.

BURROUGHS, B., y RAMA, P. (2015). The eSports Trojan horse: Twitch and streaming futures. Journal For Virtual Worlds Research, 8(2). doi.org/10.4101/jvwr.v8i2.7176

CARRILLO, J.A. (2015). La dimensión social de los videojuegos 'online': de las comunidades de jugadores a los 'e-sports'. Index.comunicación: Revista científica en el ámbito de la Comunicación Aplicada, 5(1), 39-51. https://bit.ly/3mE83D5

CASTRO-MARIÑO, D. (2018). La audiencia social y el mundo narrativo de la ficción: análisis de los comentarios de los fans y community managers sobre la ficción televisiva y webseries españolas. Palabra Clave, 21(1), 86110. doi.org/10.5294/pacla.2018.21.1.5.

DAWKINS, R. (1976). El gen egoísta. Barcelona: Labor.

DEVANEY, S.A. (2015). Understanding the millennial generation. Journal of financial service professionals, 69(6), 11-14. https://bit.ly/3EZFE23

DiWANJI, V., ReEd, A., Ferchaud, A., SeiberT, J., Weinbrecht, V., y Sellers, N. (2020). Don't just watch, join in: Exploring information behavior and copresence on Twitch. Computers in Human Behavior, 105.

doi.org/10.1016/j.chb.2019.106221

EUROPA PRESS (2021). La audiencia de Twitch crece un 16,5\% en el primer trimestre de 2021. Europa Press. https: // bit.ly/2YvrKoo

GANDOLFI, E. (2016). To watch or to play, it is in the game: The game culture on Twitch. Tv among performers, plays and audiences. Journal of Gaming \& Virtual Worlds, 8(1), 63-82. doi.org/10.1386/jgvw.8.1.63_1

GARCÍA-LEIVA, M.T. (2021). VoD platforms and prominence: a European regulatory approach. Media International Australia, 180(1), 101-115.

doi.org/10.1177/1329878X20967456

GoDOY, J.D. (21 de marzo de 2021). La transmisión de videojuegos y deportes electrónicos atraerá a mil millones de espectadores para 2025. El País. https://bit.ly/3sbUGKT

Gros, D., WANNER, B., HACHENHOLT, A., ZAWADZKI, P., y KNAUTZ, K. (2017). World of streaming. Motivation and gratification on Twitch. In International Conference on Social Computing and Social Media, 44-57. Springer, Cham. https://bit.ly/33SsIQpi

GUTIÉRREZ, J.F., y CUARTERO, A. (2020). El auge de Twitch: nuevas ofertas audiovisuales y cambios del consumo televisivo entre la audiencia juvenil. Ámbitos. Revista Internacional de Comunicación, 50, 159-175.

doi.org/10.12795/Ambitos.2020.i50.11 
HALPERn, D., QUINTAS-FroufE, N., y FERnÁNDEZ-MEDINA, F. (2016). Interacciones entre la televisión y su audiencia social: hacia una conceptualización comunicacional. Profesional De La Información, 25(3), 367-375. doi.org/10.3145/epi.2016.may.06

HAMILTON, W.A., GARRETSON, O., y KERNE, A. (2014). Streaming on twitch: fostering participatory communities of play within live mixed media. In Proceedings of the SIGCHI conference on human factors in computing systems, 1315-1324. doi.org/10.1145/2556288.2557048

HilverT-Bruce, Z., NeILl, J.T., SJÖBlOM, M., y HAMARI, J. (2018). Social motivations of live-streaming viewer engagement on Twitch. Computers in Human Behavior, 84, 58-67. doi.org/10.1016/j.chb.2018.02.013

HINE, C. (2015). Ethnography for the Internet: Embedded, embodied and everyday. Nueva York: Bloomsbury Academic.

IAB SPAIN (2021). Estudio anual de redes sociales 2021. Interactive Advertising Bureau. https://bit.ly/2sGLoL1

JENKINS, H., ITO, M., y BoYD, D. (2015). Participatory culture in a networked era: A conversation on youth, learning, commerce, and politics. Cambridge: Polity Press.

KARBAUM, G. (2018). Narrativas social media y el prosumidor mediático. Correspondencias \& Análisis, 8, 219-238. https: / / bit.ly/2SLINiY

LACALLE, C., y GóMEZ, B. (2017). La recepción televisiva española en la era multipantalla. Comunicación y Sociedad, (30), 197-216. https: / / bit.ly/3w1dkYe

LASTRA, A. (2016). El poder del prosumidor. Identificación de sus necesidades y repercusión en la producción audiovisual transmedia. Revista ICONO14 Revista científica de Comunicación y Tecnologías emergentes, 14(1), 71-94. doi.org/10.7195/ri14.v14i1.902

LAZO, C.M. (2017). Los jóvenes en la cultura digital. Revista Internacional de Comunicación y Desarrollo (RICD), 2(5), 23-28.

doi.org/10.15304/ricd.2.5.3563

LLOPIS-AMORÓS, M.P., GIL-SAURA, I., RuIZ-MolinA, M.E., y FuENTES-BlasCo, M. (2019). Social media communications and festival brand equity: Millennials vs Centennials. Journal of Hospitality and Tourism Management, 40, 134144. doi.org/10.1016/j.jhtm.2019.08.002

MARTínEZ-SALA, A.M., BARRIENTOS-BÁEZ, A., y CALVEDILla DOMÍnguEZ, D. (2021). Fandom televisivo. Estudio de su impacto en la estrategia de comunicación en redes sociales de Netflix. Revista de Comunicación de la SEECI, 54, 57-80. doi.org/10.15198/seeci.2021.54.e689 
MARTÍNEZ, S.M., y MENA, S. (2013). Televisión en Internet. Introducción y prognosis de una revolución en el mercado audiovisual. Ámbitos: Revista Internacional de Comunicación, 22, 1-12.

http://hdl.handle.net/11441/66758

MASIP, P., RUIZ-CABALLERO, C., y SUAU, J. (2019). Active audiences and social discussion on the digital public sphere. Review article. Profesional De La Información, 28(2). doi.org/10.3145/epi.2019.mar.04

MiKOS, L. (2016). Digital media platforms and the use of TV content: Binge watching and video-on-demand in Germany. Media and Communication, 4(3), 154-161. doi.org/10.17645/mac.v4i3.542

MUÑOZ-SERRANO, A. (2020). El cine del S. XXI: plataformas VOD vs cine de salas. https://bit.ly/3oIlhBj

OH, S., KIM, J., JI, H., PARK, E., HAN, J., Ko, M., y LEE, M. (2020). Cross-cultural comparison of interactive streaming services: Evidence from Twitch. Telematics and Informatics, 55. doi.org/10.1016/j.tele.2020.101434

PARVUlESCU, C. (2020). World Cinema, VoD Platforms and the Western Demand. Studies in World Cinema, 1(1), 53-59.

doi.org/10.1163/26659891-0000A001

PIRES DE SÁ, F. (2018). Researching co-viewing on social media and instant messaging applications: Ethics and challenges. Comunicaçao e Sociedade, 33, 409-424. doi.org/10.17231/comsoc.33(2018).2924

PRAKASHYADAV, G., y JYOTSNA, R. (2017). The Generation Z and their social media usage: A review and a research outline. Global Journal of Enterprise Information System, 9(2), 110-116. doi.org/10.18311/gjeis/2017/15748

RAMOS MÉNDEZ, D., y ORTEGA-MOHEDANO, F. (2017). La revolución en los hábitos de uso y consumo de video en teléfonos inteligentes entre usuarios Millenials, la encrucijada revelada. Revista Latina de Comunicación Social, 72, 704-718. doi.org/10.4185/RLCS-2017-1187

RANGEL, C., y VELASCO, M.J.C. (2017). Estudio de la evolución y tendencias de la comunicación estratégica integral. aDResearch: Revista Internacional de Investigación en Comunicación, (16), 8-33. https: / / bit.ly/3y3b4Sj

RUBIO-ROMERO, J., JIMÉNEZ, J.M., y BARÓN-DULCE, G. (2019). Las redes sociales digitales como espacios de sociabilidad de los adolescentes. El caso del colegio Escolapios de Aluche. Revista Mediterránea de Comunicación, 10(2), 85-99. http://hdl.handle.net/10045/91367

RUIZ, J.A., CÁCERES, M.D., y BRÄNDLE, G. (2010). ¿Se están modificando los hábitos de consumo audiovisual? El consumo pasivo de televisión en la era de la interactividad. En E. Said Hung (Ed.), Diálogos y desafíos euro- 
latinoamericanos (pp. 211-227). Universidad del Norte. https://bit.ly/3FDJTkX

SAlAVERRÍA, R., GARCíA, J.A., y MASIP, P. (2008). Media Convergence as a Research Concept: A Proposal for Its Theoretical and Operational Definition. Barcelona: ECREA.

SÁNCHEZ-MAROTO, E. (2018). Ahora elijo yo lo que quiero ver. Las plataformas VOD: perfil de usuario y mix de comunicación. http://uvadoc.uva.es/handle/10324/34464

SHARMA, A. (2019). Consumer behaviour and centennials. En V. Singh (Ed.), Marketing to Centennials in Digital World (pp. 37-49). International Conference on Marketing.

SJÖBLOM, M., y HAMARI, J. (2017). Why do people watch others play video games? An empirical study on the motivations of Twitch users. Computers in human behavior, 75, 985-996. doi.org/10.1016/j.chb.2016.10.019

TAJFEL, H., y TURNER, J. (1986). The social identity theory of intergroup behavior. In S. Worchel, y W.G. Austin (Eds.), Psychology of intergroup relation (pp. 7-24). Chicago: Hall Publishers.

TURNER, A. (2015). Generation Z: Technology and social interest. The journal of individual Psychology, 71(2), 103-113. doi.org/10.1353/jip.2015.0021 